\title{
Effectiveness of ATP bioluminescence assay for presumptive identification of microorganisms in hospital water sources
}

\author{
Máira Gazzola Arroyo ${ }^{1 *}$, Adriano Menis Ferreira ${ }^{2}$, Oleci Pereira Frota ${ }^{2}$, Marcelo Alessandro Rigotti ${ }^{3}$, \\ Denise de Andrade ${ }^{4}$, Natalia Seron Brizzotti ${ }^{5}$, Jacqueline Tanury Macruz Peresi ${ }^{6}$, Elza Maria Castilho ${ }^{5}$ \\ and Margarete Teresa Gottardo de Almeida ${ }^{5}$
}

\begin{abstract}
Background: Laboratory analysis of organisms in water include arduous methods, such as the multiple tube and membrane filter. The ATP bioluminescence system, proposes a new way of measuring cellular material in water by measuring adenosine triphosphate (ATP) levels, which are expressed in relative light units (RLU). The ATP bioluminescence assay has been increasingly used to assess the microbiological safety of the hospital environment. However, there are few studies investigating the use of this methodology to evaluate the microbiological quality of water. The objective of the present study was to verify whether ATP, as measured by the $3 \mathrm{M}^{\mathrm{TM}}$ Clean-Trace Water ${ }^{\mathrm{TM}}$ ATP test, can be used as an alternative tool for presumptive testing for the presence of microorganisms in hospital water.
\end{abstract}

Methods: Water samples ( $N=88$ ) were collected from faucets (74) and water purifiers (14) in a university hospital. The sample were filtered by the membrane filter technique $(100 \mathrm{~mL}$ for bacterial analysis and $100 \mathrm{~mL}$ for fungal analysis) and then submitted to ATP bioluminescence assay to the determine quantity of RLU in each sample. In order to compare RLU and the presence of microorganisms, a receiver operating characteristic (ROC) curve was used to calculate sensitivity and specificity (levels higher than 90\% were considered significant). In addition, control tests were conducted to compare RLU to the quantities of bacterial and fungal organisms added to distilled water (ANOVA and Tukey's tests; $p \leq 0.05$ ). This inoculum was compared to RLU emission, and the data were analyzed by calculating the Pearson's correlation coefficient, with a 95\% confidence interval.

Results: In the present study, $94.3 \%$ of the water samples presented bacterial growth. Of these, $15.6 \%$ showed heterotrophic bacteria above recommended levels and fungal contamination was detected in $55.6 \%$ of samples. Sensitivity and specificity of the samples were not significant $(<90 \%)$, and the correlation between ATP and the presence of these microorganisms in the samples (hospital water) was not significant, whereas, in distilled water, the results revealed a significant difference $(p<0.0001)$.

Conclusions: These results demonstrated that the ATP test cannot be used as an alternative tool for presumptive assessment of the presence of microorganisms in water.

Keywords: Adenosine triphosphate, Bacteria, Fungi, Hospital, Water

\footnotetext{
* Correspondence: mairagarroyo@gmail.com

${ }^{1}$ Graduate Program in Microbiology, São Paulo State University, Street

Cristóvão Colombo, 2265, 15054-000, São José do Rio Preto, São Paulo, Brazil

Full list of author information is available at the end of the article
} 


\section{Background}

The presence of organisms in drinking water is assessed in laboratory analysis by qualitative and quantitative criteria [1]. Initial investigations have included consistent but arduous methods, such as the multiple tube method, involving serial analysis of water samples. Subsequent studies have included alternative, less laborious methods of quantitative and qualitative analysis that use chromogenic and fluorogenic substrates and maintain high specificity and sensitivity along with speed [2, 3]. Among these methods, the membrane filter method stands out. It is considered a feasible laboratory procedure that allows for bacterial colony counts [1].

Another methodology, similar to the ATP bioluminescence system, has been proposed as a new method of measuring cellular material in water by measuring levels of adenosine triphosphate (ATP) [4].

One of the major advantages of ATP detection is that it is fast and easy to carry out [5-7]. However, there are also some disadvantages, such as low sensitivity and inability to differentiate extracellular and intracellular ATP [7-10]. Dead cells, blood, excretions, human secretions, food and other organic materials are considered extracellular ATP, whereas intracellular ATP is detected by means of viable microorganisms $[7,10,11]$.

Studies comparing the traditional methodology (colony-forming units, - CFU) with ATP detection have shown divergent results, indicating the need for more research to establish better understanding of the relationship between microorganism counts and ATP. Lee et al. [12] and Bushon et al. [13] found good correlations between ATP and CFU, but other studies [14, 15] found no significant association.

Considering the high incidence of waterborne diseases in the general population, it is necessary to establish faster and more specific protocols for microbiological investigation of water, in order to adopt control measures. The objective of the present study was to verify whether ATP bioluminescence can be used as an alternative methodology for presumptive testing for presence of microorganisms in water, by confirming that there is a correlation between RLU and the presence of these microorganisms.

\section{Methods}

\section{Collection of samples}

Water samples of $200 \mathrm{~mL}$ each $(n=88)$ were collected from faucets (74) and water purifiers (14) (both of subterranean origin) at a university hospital in the state of São Paulo, Brazil; the origin of the water within the hospital is shown in Table 1. For each sample, $100 \mathrm{~mL}$ was submitted to bacterial analysis and $100 \mathrm{~mL}$ to fungal analysis.

Eight samples were collected from each floor (ground to 8th floors), with the exception of the 3rd and 7th floors, where 16 samples were collected from each. The samples were placed in sterile Whirl-Pak ${ }^{\odot}$ Thio-Bags $^{\circ}$ with sodium thiosulfate $1.8 \%$ to neutralize the disinfectant activity of chlorine in chlorinated samples. The bags were transported in isothermal boxes to the hospital's microbiology laboratory $[1,16]$.

\section{Filtration of the samples and microbiological analysis}

According to standard methodology $[1,16]$, immediately after sample collection, $100 \mathrm{~mL}$ of each sample were filtered through a nitrocellulose membrane $(0.45 \mu \mathrm{m})$ plated in plate count agar medium (Difco Laboratories), and incubated for $48 \mathrm{~h}$ at $35^{\circ} \mathrm{C}$.

At the same time, the other $100 \mathrm{~mL}$ of each sample were filtered. After the filtration process, the membrane was transferred to a petri dish with Sabouraud dextrose agar (Difco Laboratories) and incubated for

Table 1 Distribution of the results according to the origin of the samples

\begin{tabular}{|c|c|c|c|c|c|c|c|c|}
\hline \multirow{2}{*}{$\begin{array}{l}\text { Location } \\
\text { Ground floor: }\end{array}$} & \multicolumn{2}{|c|}{$\begin{array}{l}\text { Number of } \\
\text { samples }\end{array}$} & \multicolumn{2}{|c|}{$\begin{array}{l}\text { Number of samples } \\
\text { with fungi }\end{array}$} & \multicolumn{2}{|c|}{$\begin{array}{l}\text { Number of samples with } \\
\text { bacteria }>500 \mathrm{CFU} / \mathrm{mL}\end{array}$} & \multicolumn{2}{|c|}{$\begin{array}{l}\text { Number of samples with free } \\
\text { chlorine residual within the limits }\end{array}$} \\
\hline & $\mathrm{F}$ & $P$ & $\mathrm{~F}$ & $P$ & $F$ & $P$ & $F$ & $P$ \\
\hline Hemodialysis & 7 & 1 & 2 & 0 & 0 & 0 & 7 & 1 \\
\hline 1st floor: Surgical center & 6 & 2 & 4 & 1 & 0 & 2 & 6 & 0 \\
\hline 2nd floor: Department of infectious diseases & 6 & 2 & 4 & 2 & 2 & 2 & 4 & 0 \\
\hline 3th floor: Oncology & 13 & 3 & 6 & 2 & 1 & 1 & 13 & 0 \\
\hline 4th floor: Pediatrics & 7 & 1 & 6 & 0 & 0 & 0 & 7 & 0 \\
\hline 5th floor: Cardiology & 6 & 2 & 3 & 0 & 0 & 2 & 6 & 0 \\
\hline 6th floor: Post-operative room & 6 & 2 & 5 & 0 & 0 & 2 & 6 & 0 \\
\hline 7th floor: Intensive care & 15 & 1 & 7 & 0 & 0 & 1 & 14 & 0 \\
\hline 8th floor: Transplant & 8 & 0 & 7 & 0 & 0 & 0 & 8 & 0 \\
\hline Total & 74 & 14 & 44 & 5 & 3 & 10 & 71 & 1 \\
\hline
\end{tabular}

$F$ faucets, $P$ purifiers, CFU colony-forming units 
$24 \mathrm{~h}$ at $30{ }^{\circ} \mathrm{C}[17,18]$. After this period, the membrane was removed from the original dish and maintained under the same thermal incubation conditions for 15 days. For purposes of comparison with the standard methods, the results were divided by 100 to express $\mathrm{CFU} / \mathrm{mL}$.

\section{Physical analysis}

Free chlorine residual content was recorded immediately after sample collection. To determine this content, $10 \mathrm{~mL}$ of the sample and $0.5 \mathrm{~mL}$ of the reagent NN diethyl-p-phenylenediamine were added to a cuvette. The mixture was stirred for homogenization and measured with an electronic colorimeter device (HI96711C - Hanna Instruments). To conform to the standards required by Regulation 2.914/11, samples must have minimum concentrations of free chlorine residual of $0.2 \mathrm{mg} / \mathrm{L}$ and maximum limits of $2 \mathrm{mg} / \mathrm{L}$ [1].

\section{ATP (bioluminescence) test and statistical analysis} Immediately after sample collection, ATP bioluminescence $\left(3 \mathrm{M}^{\mathrm{mx}}\right.$ Clean-Trace Water ${ }^{\mathrm{Tn}}$ ATP system) was used to the quantify RLU in all samples. In this system, a specialized rod is inserted into the water sample and then placed in a tube with a reagent that unleashes a bioluminescence reaction; luciferase is the revealing enzyme and luciferin, the substrate. Light is emitted in the presence of ATP, which is detected by specialized equipment (a luminometer). Concentrations of ATP are directly proportional to the quantity of cellular material and are expressed in relative light units (RLU) [4].

In order to compare RLU and the presence of microorganisms, a receiver operating characteristic (ROC) curve was used to calculate sensitivity and specificity: levels higher than $90 \%$ were considered significant.

Control tests were conducted in order to compare RLU with the quantity of bacterial and fungal organisms present in distilled water, which is free of microorganisms and cellular material (ANOVA and Tukey's tests, when $p$ was significant: $p \leq 0.05)$. Thus, pure Staphylococcus aureus (American Type Culture Collection ATCC 25923) and Candida parapsilosis cultures (ATCC 22019) were reactivated on nutrient agar for $24 \mathrm{~h}$ at $37^{\circ} \mathrm{C}$. Colonies were placed in tubes containing $5 \mathrm{ml}$ sterile distilled water to achieve concentrations (0.5 to 10) according to the McFarland standards. Dilutions were performed to achieve a dilution of $10^{-10}$ from the lower concentration. From these concentrations, $100 \mu \mathrm{l}$ were transferred to polystyrene dishes and the absorbance value was checked (Biospectro spectrophotometer). This inoculum was compared with RLU emission, and the data were analyzed by calculating Pearson's correlation coefficient, with a 95\% confidence interval.

\section{Results}

Table 1 shows the distribution of the results obtained, according to the origin of the samples. Eighty-three (94.3\%) samples presented bacterial growth: 69 (83.1\%) from faucets and 14 (16.9\%) from purifiers. Of these, 13 (15.6\%) presented heterotrophic organism levels above those recommended by the Brazilian Ministry of Health $(\leq 500 \mathrm{CFU} / \mathrm{mL})$. There was also fungal contamination in $49(55.6 \%)$ water samples.

In relation to the data for RLU, 36 samples presented exclusive bacterial growth. This can be explained by the fact that no fungal growth was observed in the Sabouraud agar medium plates, which favor fungal growth. If neither yeast nor mold grew in the plates with a medium that is selective for fungi, it can be concluded that there was only bacterial growth in the plate count agar medium, with a mean RLU value of 14.4. Only two samples presented exclusive fungal growth, with a mean RLU of 23. Water samples that presented simultaneous growth of two types of microorganisms $(N=47)$ had a mean RLU value of 16.5 . For the samples that showed no microorganism growth $(N=3)$, the mean RLU value was 8.6. The minimum and maximum RLU values found in the samples were 4 (3rd and 7th floor) and 141 (2nd floor). An ROC curve was used to establish a cutoff point of RLU values to detect contaminated water. However, the sensitivity and specificity of the samples were not significant, as most had results lower than $90 \%$ (Fig. 1).

Pearson's correlation coefficient between RLU measurement and microbial concentration (absorbance) in distilled water revealed results with significant differences, $p<0.0001$ (Figs. 2 and 3).

Minimum and maximum limits of detection are $10^{-10}$ and 10. For $S$. aureus, the corresponding RLU value for the $10^{-10}$ dilution was 18 ; for the concentration of 10 , it

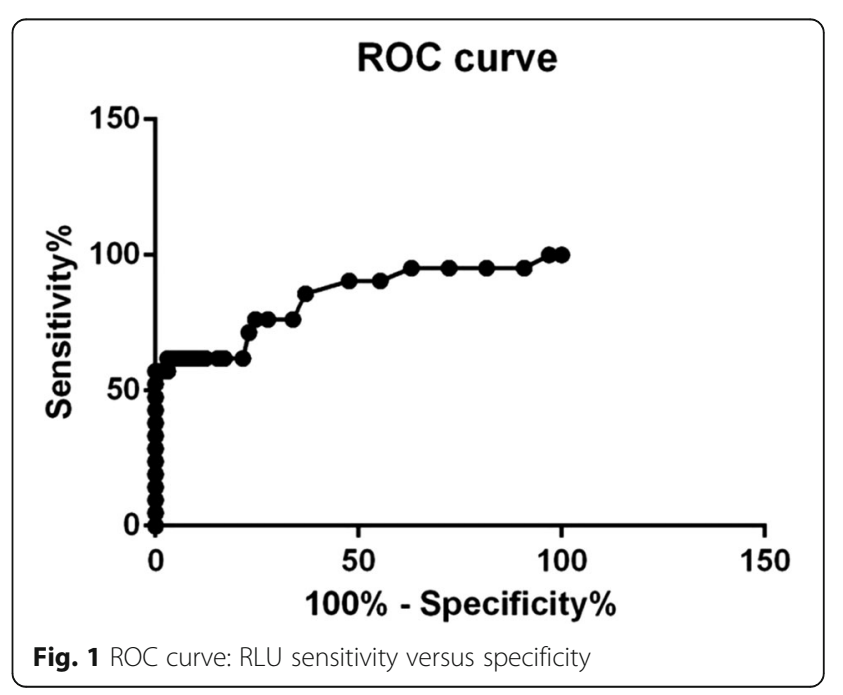




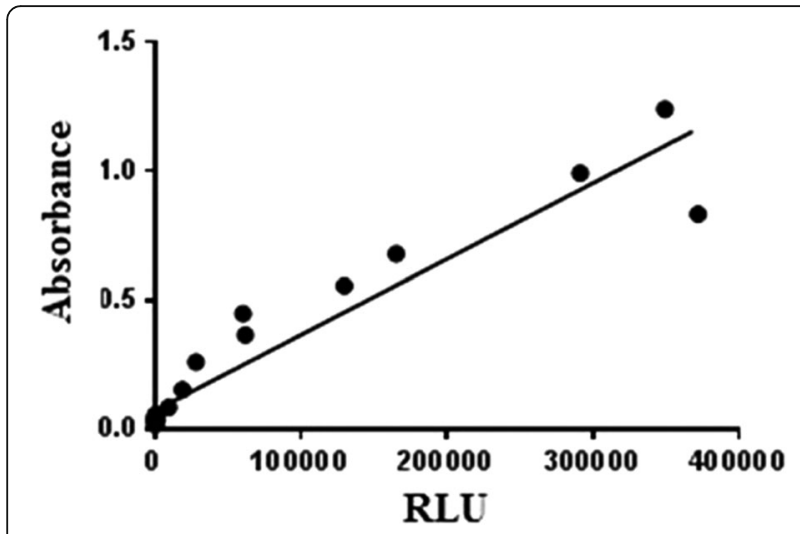

Fig. 2 Correlation between microbial concentration of S. aureus (absorbance) and RLU

was 349,333. For C. parapsilosis, the corresponding RLU values were 37 and 780,198 for the minimum and maximum limits of detection, respectively.

\section{Discussion}

Lack of significant correlations between RLU and the presence of bacteria and fungi (Fig. 1) could be due to several factors, such as variations in microbial cell size and cell development stages, as has been described by other authors [7]. A sample with few yeast cells can result in high levels of RLU (ATP), and one with many yeast cells can present low levels of RLU. The effect of environmental stress on RLU emission has been investigated in other studies $[19,20]$. On study examined the effects of hydric stress and nutritional conditions on Pseudomonas paucimobilis present in soil. The findings demonstrated that ATP content increased in dry soil or with the introduction of glucose and ammonium salts [19].

Furthermore, in the present study, RLU was detected even in samples in which fungi and bacteria were not

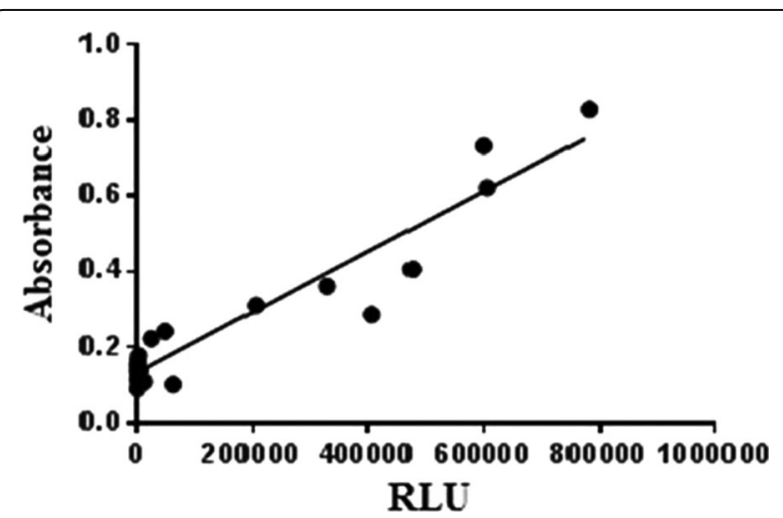

Fig. 3 Correlation between microbial concentration of Candida parapsilosis absorbance) and RLU isolated. This may be explained by the presence of other microorganisms, such as protozoa or anaerobic bacteria. In addition, the chlorine present in water (Table 1) could inhibit some microorganisms for culture, but ATP was present. Similarly, some bacteria that would grow at lower or higher temperatures did not grow in the culture media, but ATP was found.

This lack of correlation could also have occurred because the system does not make a distinction between intracellular and extracellular ATP. Both intracellular and extracellular ATP were measured, which does not correspond to the microorganisms present in the samples. Biological systems have other nonbacterial sources of ATP and, consequently, microbial ATP represents only a portion of the ATP responsible for bioluminescence. Interference from ATP of nonmicrobial origin may limit the sensitivity of the method and lead to false positives [21-23]. However, whether the samples included intracellular or extracellular ATP, the results of the present study indicate that, in addition to including viable microorganisms, the samples also contained secretions and excretions, making the water unfit for consumption and implying health problems.

In relation to the average RLU in the samples with exclusive fungal growth, there was higher-than-average RLU in samples with exclusive bacterial growth, or growth of both bacteria and fungi. A possible explanation is that in the samples with exclusive fungal growth, free chlorine residual content was within the established limits (Table 1), and some bacteria that were present could not be grown, but their ATP was detected, indicating high levels of RLU.

Perhaps for these reasons, discrepancies between the results of the ATP bioluminescence and the presence of microorganism in the samples indicate that this correlation is still questionable and needs more research in order to gain consensus.

When compared to samples of distilled water (control test) contaminated with ATCC from S. aureus and $C$. parapsilosis, and considering the correspondence of these samples' absorbance with RLU, the results were significant; when the inoculums increased, so did RLU levels (Figs. 2 and 3). In this situation, distilled water does not have interferents or microorganisms other than those that have been introduced, which could explain the significant results obtained.

\section{Conclusions}

The ATP bioluminescence system used in this study showed low correlations with microbiological cultures. Therefore, this technology cannot be used as an alternative methodology for presumptive testing for the presence of microorganisms in water. 


\section{Abbreviations}

ATCC: American Type Culture Collection; ATP: Adenosine triphosphate; C. parapsilosis: Candida parapsilosis; CFU: Colony-forming units; DPD: NN diethyl paraphenylene diamine; mL: Milliliter; RLU: Relative light units; ROC: Receiver operating characteristic; S. aureus: Staphylococcus aureus

\section{Acknowledgments}

The authors would like to thank Dr. Lilian Castiglioni from the Department of Epidemiology and Public Health of the School of Medicine of São José do Rio Preto, São Paulo, Brazil, for the support provided in statistical analyses.

\section{Funding}

The study had no sources of funding.

\section{Availability of data and materia}

All data and materials are available upon request.

\section{Authors' contributions}

MGA contributed with sample collection and processing, data interpretation, writing and drafting of the article. AMF collaborated in the original idea, concept, design and also reviewed the article for publication. NSB contributed with sample identification, interpretation of data and critical analysis. OPF reviewed the references, conducted critical analysis and drafted the article. DA, JTMP, EMC and MAR participated in the critical analysis and in drafting the article. MTGA contributed to all stages of the process, mainly writing and editing the final version to be published. All authors read and approved the final manuscript.

\section{Ethics approval and consent to participate} Not applicable.

\section{Consent for publication}

Not applicable.

\section{Competing interests}

The authors declare that they have no competing interests.

\section{Publisher's Note}

Springer Nature remains neutral with regard to jurisdictional claims in published maps and institutional affiliations.

\section{Author details}

${ }^{1}$ Graduate Program in Microbiology, São Paulo State University, Street Cristóvão Colombo, 2265, 15054-000, São José do Rio Preto, São Paulo, Brazil. ${ }^{2}$ Master and Doctoral Graduate Program in Health and Development in the West Central Region and Master Graduate Program in Nursing, Federal University of Mato Grosso do Sul, Av. Costa and Silva, s/n, 79070-900, Campo Grande, Mato Grosso do Sul, Brazil. ${ }^{3}$ Undergraduate Program in Nursing, Federal University of Mato Grosso do Sul, Av. Ranulpho Marques Leal, 3484 79610-100, Três Lagoas, Mato Grosso do Sul, Brazil. ${ }^{4}$ Department of General and Specialized Nursing, Ribeirão Preto College of Nursing, WHO Collaborating Centre for Nursing Research Development, University of São Paulo, Av. Bandeirantes, 3900, 14040-902, Ribeirão Preto, São Paulo, Brazil. ${ }^{5}$ Department of Infectious and Parasitic Diseases, Faculty of Medicine of São José do Rio Preto, Av. Brg. Faria Lima, 5416, 15090-000, São José do Rio Preto, São Paulo, Brazil. ${ }^{6}$ Center of Regional Laboratory of São José do Rio Preto, Adolfo Lutz Institute, Street Rua Alberto Sufredini Bertoni, 2325, 15060-020, São José do Rio Preto, São Paulo, Brazil.

Received: 27 January 2017 Accepted: 22 June 2017

Published online: 30 June 2017

\section{References}

1. American Public Health Association (APHA). Standard methods for examination of water and wastewater. Washington: American Public Health Association; 2012. https://www.mwa.co.th/download/file_upload/SMWW_ 1000-3000.pdf. Accessed 5 Apr 2016.

2. Adetunde LA, Glover RLK. Evaluation of bacteriological quality of drinking water used by selected secondary schools in Navrongo in Kassena Nankana district of upper east region of Ghana. Prime J Microbiol Res. 2011;1:47-51.
3. Rompré A, Servais $P$, Baudart J, de-Roubin MR, Laurent P. Detection and enumeration of coliforms in drinking water: current methods and emerging approaches. J Microbiol Methods. 2002;49:31-54.

4. Boyce JM, Havill NL, Dumigan DG, Golebiewski M, Balogun O, Rizvani R. Monitoring the effectiveness of hospital cleaning practices by use of an adenosine triphosphate bioluminescence assay. Infect Control Hosp Epidemiol. 2009;30:678-84.

5. Van der Kooji D, Veenendaal HR, Baars-Lorist C, Van der Klift WD, Drost CY. Biofilm formation on surfaces of glass and Teflon exposed to treated water. Water Res. 1995;29:1655-62.

6. Velten S, Hammes F, Boller M, Egli T. Rapid and direct estimation of active biomass on granular activated carbon through adenosine tri-phosphate (ATP) determination. Water Res. 2007:41:1973-83.

7. Venkateswaran K, Hattori N, La Duc MT, Kern R. ATP as a biomarker of viable microorganisms in clean-room facilities. J Microbiol Methods. 2003:52:367-77.

8. Hammes F, Berney M, Wang Y, Vital M, Köster O, Egli T. Flow-cytometric total bacterial cell counts as a descriptive microbiological parameter for drinking water treatment processes. Water Res. 2008;42:269-77.

9. Hammes F, Goldschmidt F, Vital M, Wang Y, Egli T. Measurement and interpretation of microbial adenosine tri-phosphate (ATP) in aquatic environments. Water Res. 2010;44:3915-23.

10. Sakakibara T, Murakami S, Hattori N, Nakajima M, Imai K. Enzymatic treatment to eliminate the extracellular ATP for improving the detectability of bacterial intracellular ATP. Anal Biochem. 1997;250:157-61.

11. Boyce JM, Havill NL, Havill HL, Mangione EBS, Dumigan DG, Moore BA. Comparison of fluorescent marker systems with 2 quantitative methods of assessing terminal cleaning practices. Infect Control Hosp Epidemiol. 2011;32:1187-93.

12. Lee J, Deininger RA, Fleece RM. Rapid determination of bacteria in pools. J Environ Health. 2001;64:9-14

13. Bushon RN, Likirdopulos CA, Brady AM. Comparison of immunomagnetic separation/adenosine triphosphate rapid method to traditional culturebased method for $E$. coli and enterococci enumeration in wastewater. Water Res. 2009;43:4940-6.

14. Mueller SA, Anderson JE, Kim BR, Ball JC. Comparison of plate counts, Petrifilm dipslides, and adenosine triphosphate bioluminescence for monitoring bacteria in cooling-tower waters. Water Environ Res. 2009:81:401-6.

15. Duda S, Baron JL, Wagener MM, Vidic RD, Stout JE. Lack of correlation between legionella colonization and microbial population quantification using heterotrophic plate count and adenosine triphosphate bioluminescence measurement. Environ Monit Assess. 2015:187:393.

16. Brazilian Ministry of Health. Protocol n² 2.914 of 12 December 2011. Protocol of potability of water for human consumption. Brazilian Official Gazette of the Union: Brasilia, Brazil. 2011. http://www.comitepci.sp.gov.br/ download/Portaria_MS_2914-11.pdf. Accessed 10 Apr 2016.

17. Hoog GS, Guarro J, Gené J, Figueras MJ. Atlas of clinical fungi. 2nd ed. Utrecht: CBS; 2000

18. Samson RA, Hoekstra ES and Frisvad JC. Introduction to food and airborne fungi. $7^{\text {th }}$ ed. United States: ASM Press; 2004

19. Fairbanks BC, Woods LE, Bryant RJ, Elliott ET, Cole CV, Coleman DC. Limitations of ATP estimates of microbial biomass. Soil Biol Biochem. $1984 ; 16: 549-58$

20. Li J, Kolling GL, Matthews KR, Chikindas ML. Cold and carbon dioxide used as multi-hurdle preservation do not induce appearance of viable but nonculturable Listeria monocytogenes. J Appl Microbiol. 2003:94:48-53.

21. Russotto V, Cortegiani A, Raineri SM, Gregoretti C, Giarratano A. Adenosine triphosphate bioluminescence in intensive care units: be careful with its use Am J Infect Control. 2016;44:732-3.

22. Larson EL, Aiello AE, Gomez-Duarte C, Lin X, Lee L, Della-Latta P, et al. Bioluminescence ATP monitoring as a surrogate marker for microbial load on hands and surfaces in the home. Food Microbiol. 2003:20:735-9.

23. Shama G, Malik DJ. The uses and abuses of rapid bioluminescence-based ATP assays. Int J Hyg Environ Health. 2013:216:115-25. 